Sains Malaysiana 47(8)(2018): 1867-1872

http://dx.doi.org/10.17576/jsm-2018-4708-27

\title{
Kelakuan Migrasi Elektrokimia Pateri SAC305 dalam Larutan Natrium Hidroksida pada Kepekatan yang Pelbagai
}

(Electrochemical Migration Behaviour of SAC305 Solder in Various Concentrations of Sodium Hydroxide Solution)

\author{
EMEE MARINA SALLEH, NORINSAN KAMIL OTHMAN* \& AZMAN JALAR
}

\begin{abstract}
ABSTRAK
Pengecilan saiz antarahubung dalam papan litar bercetak (PCB) membawa kepada migrasi elektrokimia (ECM) dan kemudiannya menyebabkan litar pintas. ECM merupakan salah satu jenis kakisan yang ketara menjejaskan kebolehtahanan kakisan kepada peralatan elektronik. Migrasi ini ialahfenomena ion logam bergerak dari satu kawasan ke kawasan yang lain di dalam medium logam, menyebabkan endapan berlaku di bahagian katod logam ataupun aloi. Justeru, kajian ini dijalankan untuk menentukan kelakuan kakisan melalui ujian titisan air (WDT) pateri bebas plumbum Sn-3.0Ag-0.5Cu (SAC305) di dalam larutan natrium hidroksida (NaOH) yang berbeza kepekatan iaitu 0.05M, 0.1M, 0.5M dan 1.0M. Purata masa-ke-kegagalan (MTTF) pateri SAC305 berkurangan apabila didedahkan kepada medium larutan NaOH yang semakin tinggi kepekatannya. Pembentukan dendrit dikesan selepas kakisan pateri SAC305 akibat proses ECM dan menyebabkan litar pintas. Hasil kakisan $\mathrm{Cu}(\mathrm{OH})_{2}$ dan $\mathrm{SnO}_{2}$ juga didapati terbentuk selepas pateri terkakis. Bopeng kecil kelihatan terbentuk terutamanya pada kepekatan yang tinggi adalah disebabkan oleh perlarutan pada anod Sn.
\end{abstract}

Kata kunci: Bahan pateri Sn-Ag-Cu; kakisan; migrasi elektrokimia; pateri tanpa plumbum; ujian titisan air

ABSTRACT

Miniaturization of the interconnection size in printed circuit board (PCB) leads to electrochemical migration (ECM) causing short circuit. ECM is a form of corrosion which significantly affects the corrosion reliability for most of the electronic equipment. Migration is a phenomenon in which the metallic ions are moving from one region to another region of metal, resulting in metal or alloy deposits at cathodic part. Hence, this study was performed in order to determine corrosion behaviour of SAC305 solder via water drop test (WDT) in various concentration of sodium hydroxide (NaOH) included $0.05 \mathrm{M}, 0.1 \mathrm{M}, 0.5 \mathrm{M}$ and $1.0 \mathrm{M}$. The results showed that mean time to failure (MTTF) of SAC305 solder reduced when the samples were exposed to higher concentration of $\mathrm{NaOH}$ solution. Formation of dendrite was observed after SAC305 solder corroded due to ECM process which resulted in short circuit. Corrosion product such as $\mathrm{Cu}(\mathrm{OH})_{2}$ and $\mathrm{SnO} \mathrm{O}_{2}$ were formed after the solder was corroded. Tiny pitting was formed especially at high concentration of NaOH which was due to dissolution of Sn anode.

Keywords: Corrosion; electrochemical migration; lead free solder; Sn-Ag-Cu solder material; water drop test

\section{PENGENALAN}

Pematerian merupakan salah satu teknologi utama untuk menyambungkan komponen mikroelektronik pada papan litar bercetak (Liew et al. 2012; Yu et al. 2006). Sambungan pateri sering terdedah kepada persekitaran yang mengakis yang akan mempercepatkan proses kakisan (Tsao 2012). Kakisan boleh berlaku disebabkan oleh kehadiran kelembapan, udara yang mengakis dan bekalan arus (Vimala et al. 2009). Akibat ketoksidan unsur plumbum $(\mathrm{Pb})$, penggunaan pateri mengandungi $\mathrm{Pb}$ telah dimansuhkan penggunaannya. Dalam kalangan pelbagai sistem aloi, Sn-Ag-Cu diiktiraf sebagai yang terbaik untuk menggantikan bahan pateri $\mathrm{Pb}$ (Anderson 2006; Lee \& Mohamad 2013). Ini kerana suhu leburnya $\left(217^{\circ} \mathrm{C}\right)$ yang lebih rendah berbanding dengan aloi eutektik binari Sn$\operatorname{Ag}\left(221^{\circ} \mathrm{C}\right)$, serta kebolehpaterian dan ciri mekanik yang lebih baik berbanding dengan aloi eutektik binari $\mathrm{Sn}-\mathrm{Cu}$ (Ma \& Suhling 2009).
Pengecilan saiz peralatan elektronik menyebabkan penggunaan bahan pateri bebas $\mathrm{Pb}$ telah mendatangkan banyak cabaran dalam pemasangan elektronik (Xue et al. 2011). Akibat kemajuan teknologi ini menyebabkan alat-alat elektronik menjadi semakin cenderung kepada kegagalan akibat kakisan (Minzari et al. 2011). Kakisan peralatan elektronik menjadi satu masalah yang sangat serius, yang mengakibatkan kerosakan dianggarkan mencapai \$5 bilion di Amerika Syarikat sahaja untuk pembaikan peralatan dan penggantian komponen (Mohanty \& Lin 2008; Vimala et al. 2009).

Migrasi elektrokimia (ECM) akibat kakisan ialah fenomena pergerakan elektrokimia yang berkaitan dengan larutan kimia dan elektrik (Jung et al. 2008; Medgyes et al. 2013). ECM boleh didefinisikan sebagai pengangkutan ion logam melalui satu akueus elektrolit di antara dua elektrod dengan kehadiran elektrik (Noh \& Fung 2008). Dalam keadaan yang konduktif, endapan berstruktur 
dendrit tumbuh daripada katod dan mengembang ke arah anod, akhirnya menyebabkan litar pintas antara keduadua elektrod (Jung et al. 2008; Minzari et al. 2011). Pembentukan dendrit pada filamen anod konduktif (CAF) bergantung kepada bentuk endapan dan syarat tertentu (Rosalbino et al. 2009). Fenomena ECM terjadi akibat kehadiran lembapan pada sistem konduktor-dielektrikkonduktor di bawah voltan pincang, lalu berlakunya proses elektrokimia dan pertumbuhan logam dendrit (Medgyes et al. 2013). Apabila kakisan berlaku pada sambungan pateri, ia akan mengubah mikrostruktur pateri yang menyebabkan karat dan tapak permulaan retak, membawa kepada kemerosotan ciri mekanik sambungan pateri (Mizari et al. 2011; Tsao 2012).

Aloi hipoeutektik Sn-3.0Ag-0.5Cu menjadi satu (Wang et al. 2012) alternatif paling sesuai untuk menggantikan bahan pateri berplumbum. Namun, sifat aloi ini terutamanya dalam medium terkakis masih belum dijelaskan secara terperinci (Yu et al. 2006). Berdasarkan kajian persuratan, pelbagai penyelidikan berkaitan kelakuan kakisan aloi bebas $\mathrm{Pb}$ dijalankan menggunakan medium berasid. Walau bagaimanapun, kajian mengenai kelakuan ECM pateri bebas $\mathrm{Pb}$ yang didedahkan kepada larutan beralkali dalam kepekatan yang berlainan adalah sangat terhad (Liew et al. 2012; Rosalbino et al. 2009). Oleh sebab itu, penyelidikan ini dijalankan untuk mengkaji kelakuan pateri aloi Sn-Ag$\mathrm{Cu}$ dalam pelbagai kepekatan larutan natrium hidroksida $(\mathrm{NaOH})$ melalui ujian titisan air (WDT).

\section{BAHAN DAN KAEDAH}

Aloi pateri SAC305 dengan komposisi 96.5\% Sn, 3\% Ag dan $0.5 \% \mathrm{Cu}$ dicetak ke papan ujian yang bercorak sikat dengan garis mendatar pada jalur konduktor adalah $0.4 \mathrm{~mm}$ dengan saiz jurang $0.2 \mathrm{~mm}$ pada substrat FR-4. Pes pateri didepositkan pada papan ujian lalu dipanaskan dengan Desktop Lead-Free Reflow Oven TYR108C. Sebelum ujian titisan air (WD) dijalankan, papan ujian, meter volt, perintang dan juga pembekal kuasa disambungkan. Selepas itu, sebanyak $15 \mu \mathrm{L}$ larutan $\mathrm{NaOH}$ (bagi setiap kepekatan $0.05 \mathrm{M}, 0.1 \mathrm{M}, 0.5 \mathrm{M}$ dan $1.0 \mathrm{M}$ ) dititiskan ke atas papan ujian dengan menggunakan mikropipet dan 10 VDC voltan digunakan. Semua sampel diuji pada suhu bilik dan dalam persekitaran yang sama. Rajah 1 menunjukkan skematik platform ujian WD.
Semasa ujian WD, pembentukan litar pintas dikesan oleh meter volt disambungkan satu perintang secara siri melalui Purata Masa-Ke-Kegagalan (MTTF). Nilai tara kegagalan ialah 0.1 VDC dan nilai perintang (R) ialah $1 \mathrm{kOhm}$. Bagi setiap kepekatan larutan, ujian wD telah dijalankan sebanyak tiga kali ujian untuk mengelakkan ralat sistematik. Masa kegagalan pateri iaitu tempoh penurunan voltan kepada 0 VDC yang diperoleh akan ditukar ke dalam saat dan seterusnya MTTF dapat dikira dengan formula:

$$
\mathrm{MTTF}=\frac{x_{1}+x_{2}+x_{3}}{3}
$$

dengan MTTF ialah purata masa-ke-kegagalan; ialah masa yang diambil daripada ujian pertama; ialah masa yang diambil daripada ujian kedua; dan ialah masa yang diambil daripada ujian ketiga.

Selepas ujian WD, papan ujian dipotongkan kepada saiz $1.0 \times 1.0 \mathrm{~cm}$ dan dianalisis menggunakan Mikroskop Optik (OM) dan Mikroskopi Elektron Imbasan Beresolusi Tinggi (FESEM) untuk mengkaji morfologi dan mikrostruktur pateri SAC305 selepas kakisan. Seterusnya, spektroskopi tenaga serakan sinar-X (EDX) digunakan dalam kajian ini untuk menganalisis komposisi unsur-unsur yang terdapat dalam sampel secara kualitatif.

\section{KEPUTUSAN DAN PERBINCANGAN}

Ujian titisan air (WD) dijalankan ke atas pateri SAC305 yang telah dicetak ke papan ujian dengan menggunakan larutan $\mathrm{NaOH}$ dalam kepekatan yang berbeza . Papan ujian yang telah dititiskan dengan larutan natrium hidroksida akan mengalami migrasi elektrokimia (ECM) sehingga berlakunya litar pintas. Purata masa-ke-kegagalan (MTTF) dapat diperoleh daripada ketiga-tiga masa kegagalan yang dicatatkan dalam Jadual 1. Nilai MTTF pateri SAC305 yang telah menjalani ujian titisan air dengan menggunakan medium larutan $0.05 \mathrm{M} \mathrm{NaOH}$ mengambil masa yang paling panjang iaitu sebanyak $2676 \mathrm{~s}$. Manakala dalam medium larutan 1.0M NaOH, MTTF pateri SAC305 paling rendah iaitu sebanyak 1736 s. Fenomena ini dapat dikaitkan tindak balas kimia pateri SAC305 dengan larutan $\mathrm{NaOH}$ dan keupayaan elektrik yang dikenali sebagai migrasi ionik atau migrasi elektrokimia (ECM)

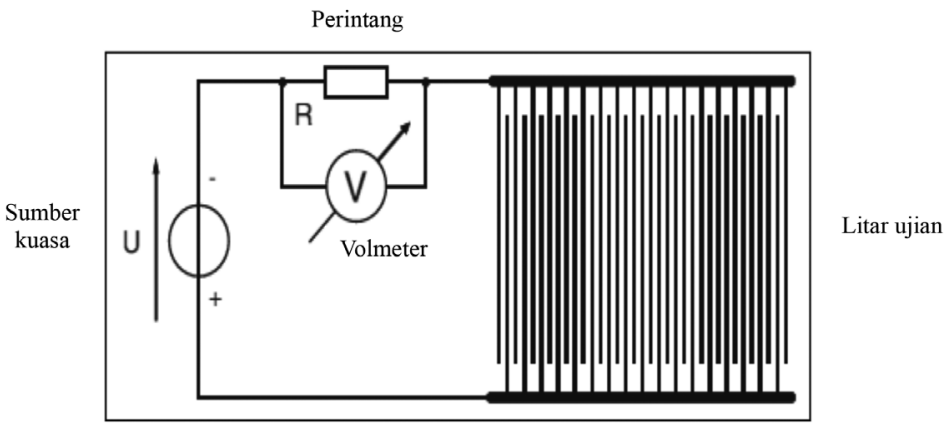

RAJAH 1. Skema platform ujian WD 
JADUAL 1. Purata masa untuk kegagalan (MTTF) pateri SAC305

\begin{tabular}{cc}
\hline $\begin{array}{c}\text { Kepekatan } \mathrm{NaOH} \\
(\mathrm{M})\end{array}$ & $\begin{array}{c}\text { Purata masa untuk kegagalan } \\
(\mathrm{s})\end{array}$ \\
\hline 0.05 & 2676 \\
0.1 & 2522 \\
0.5 & 2043 \\
1.0 & 1736 \\
\hline
\end{tabular}

(Mohanty \& Lin 2008). Keputusan ini menunjukkan aloi pateri SAC305 dipercayai mengalami ECM dengan logam ion telah bermigrasi daripada anod ke katod yang menyebabkan penyusutan nilai voltan kepada $0 \mathrm{~V}$ dan seterusnya mengakibatkan kegagalan pada keseluruhan peranti (Rosalbino et al. 2009).

Fenomena ECM boleh dikaitkan secara langsung dengan kecenderungan pateri SAC305 terhadap kakisan. Rajah 2 menunjukkan bahawa MTTF pateri SAC305 semakin menurun apabila kepekatan medium larutan $\mathrm{NaOH}$ yang digunakan semakin meningkat. Hal ini disebabkan oleh kandungan ion $\mathrm{OH}^{-}$yang tinggi menyebabkan tindak balas kimia berlaku dengan kadar yang lebih tinggi meningkatkan enapan ion di bahagian katod pateri tersebut, seterusnya mengakibatkan kegagalan pada pateri yang diuji. Oleh itu, hasil keputusan tersebut dapat disimpulkan bahawa migrasi elektron pateri SAC305 lebih mudah berlaku apabila didedahkan dalam medium $\mathrm{NaOH}$ yang lebih tinggi kepekatannya. Urutan berlakunya ECM pada pateri SAC305 di antara $0.05 \mathrm{M}, 0.1 \mathrm{M}, 0.5 \mathrm{M}$, serta $1.0 \mathrm{M}$ $\mathrm{NaOH}$ telah didapati dalam kajian ini, iaitu:

$$
1.0 \mathrm{M}>0.5 \mathrm{M}>0.1 \mathrm{M}>0.05 \mathrm{M}
$$
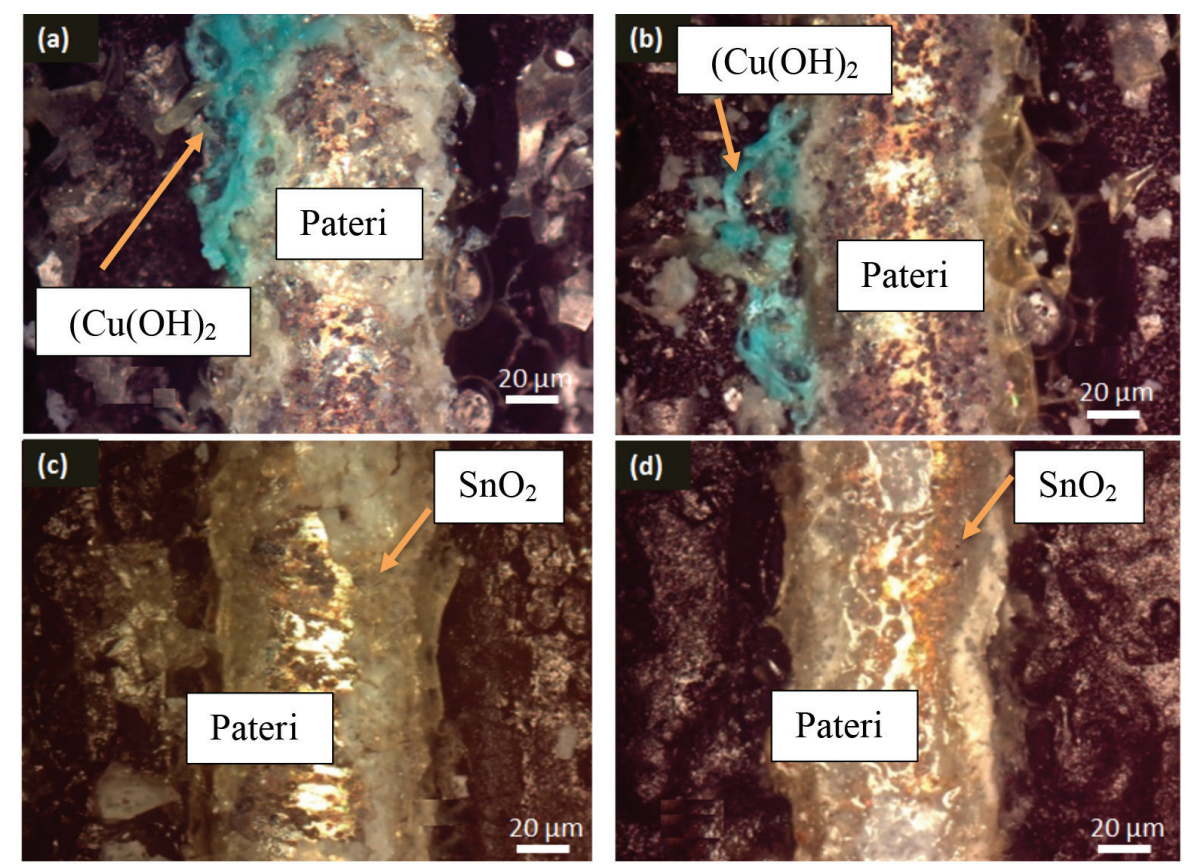

RAJAH 3. Morfologi permukaan terkaksi bagi pateri SAC305 yang didedahkan kepada (a) 0.05M,

(b) $0.1 \mathrm{M}$, (c) $0.5 \mathrm{M} \mathrm{NaOH}$ dan (d) $1.0 \mathrm{M} \mathrm{NaOH}$

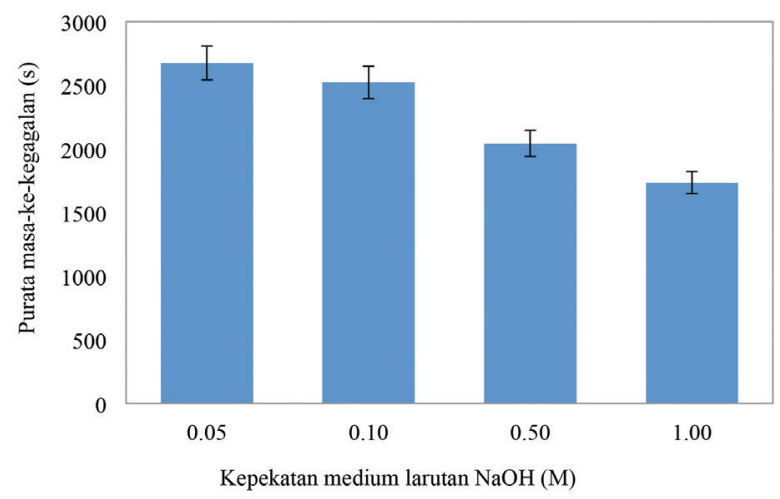

RAJAH 2. Graf purata masa-ke-kegagalan bagi pateri SAC305 yang telah menjalani ujian titisan air dengan kepekatan medium larutan $\mathrm{NaOH}$ yang berbeza

Selain itu, sisihan piawai bagi pateri SAC305 yang didedahkan dalam kepekatan larutan $\mathrm{NaOH}$ yang berbeza diwakili dengan menggunakan bar ralat. Berdasarkan aras keyakinan $3 \sigma$, keputusan ini menunjukkan bahawa proses ECM adalah bukan proses pegun mahupun proses yang berterusan kerana panjang bar ralat yang ditunjukkan tidak sama dan diandaikan cenderung ke arah taburan normal (Minzari et al. 2011; Nazeri et al. 2012).

Dalam kajian ini, morfologi dan mikrostruktur pateri SAC305 dikaji selepas didedahkan kepada larutan $\mathrm{NaOH}$ yang berlainan kepekatan. Morfologi pateri SAC305 diperhatikan dengan menggunakan mikroskop optik (OM) dan mikroskopi elektron imbasan beresolusi tinggi (FESEM). Rajah 3(a) dan 3(b) menunjukkan pembentukan hasil kakisan yang berwarna biru pada permukaan pateri SAC305 yang telah didedahkan kepada $0.05 \mathrm{M} \mathrm{NaOH}$ 
dan 0.1 M NaOH. Menurut Medgyes et al. (2013), hasil kakisan yang berwarna biru ini adalah kuprum hidroksida $\left(\mathrm{Cu}(\mathrm{OH})_{2}\right)$ yang terbentuk akibat daripada tindak balas pateri SAC305 dalam keadaan akueus. Tambahan pula, pateri SAC305 yang telah menjalani ujian WD dengan $0.05 \mathrm{M} \mathrm{NaOH}$ terbentuk lebih banyak kebiruan hasil kakisan berbanding dengan 0.1 M NaOH. Manakala, hanya pembentukan berwarna kelabu didapati pada pemukaan pateri SAC305 yang telah didedahkan kepada $0.5 \mathrm{M} \mathrm{NaOH}$ dan 1.0M NaOH. Hal ini menunjukkan pembentukan hasil kakisan pada permukaan pateri telah didominasi oleh pembentukan stanum dioksida $\left(\mathrm{SnO}_{2}\right)$ yang lebih stabil pada kepekatan larutan $\mathrm{NaOH}$ yang lebih tinggi. Selain itu, mendakan seperti lapisan kabur putih yang mengandungi unsur $\mathrm{Sn}$ dan O juga terbentuk pada setiap sampel tersebut di samping pembentukan dendrit. Oleh itu, keadaan ini adalah sangat sukar untuk mengenal pasti kewujudan struktur dendrit yang halus dalam lapisan kabur putih (Minzari et al. 2011; Noh \& Fung 2008).

Rajah 4 menunjukkan pembentukan dendrit pada pateri SAC305 selepas menjalani ujian WD dengan menggunakan medium larutan $\mathrm{NaOH}$. Mikrostruktur dendrit mempamerkan batang lurus dengan cawangan dalam arah menegak dan cawangan ini juga mempunyai beberapa cabang kecil (Jung et al. 2008) menunjukkan pertumbuhan dendrit berlaku akibat perlarutan ion logam pada anod dan kemudiannya keluar ke katod. Jadi, penebat di antara katod dan anod itu pecah akibat pertumbuhan dendrit, lalu menyebabkan sambungan elektrik antara katod dan anod berlaku.
Tsao (2012) menerangkan bahawa tindak balas yang boleh berlaku pada katod ialah penurunan oksigen.

$$
\begin{array}{ll}
\text { Katod: } & \mathrm{O}_{2}+2 \mathrm{H}_{2} \mathrm{O}+4 \mathrm{e}^{-} \rightarrow 4 \mathrm{OH}^{-} \\
& 2 \mathrm{H}_{2} \mathrm{O}+2 \mathrm{e}^{-} \rightarrow \mathrm{H}_{2}+2 \mathrm{OH}^{-}
\end{array}
$$

Buih-buih hidrogen $\left(\mathrm{H}_{2}\right)$ akan dilepaskan daripada katod semasa tindak balas ini adalah akibat daripada pembebasan hidrogen pada katod. Walau bagaimanapun, tindak balas pada anod agak merumitkan. Sebahagian tindak balas pada anod yang berlaku adalah seperti yang berikut:

$$
\begin{array}{ll}
\text { Anod: } & \mathrm{Sn}+2 \mathrm{OH}^{-} \rightarrow \mathrm{Sn}(\mathrm{OH})_{2}+2 \mathrm{e}^{-} \\
& \mathrm{Sn}+4 \mathrm{H}_{2} \mathrm{O} \rightarrow \mathrm{Sn}(\mathrm{OH})_{4}+4 \mathrm{e}^{-}+4 \mathrm{H}^{+}
\end{array}
$$

Kemudian, $\mathrm{Sn}(\mathrm{OH})_{2}$ dan $\mathrm{Sn}(\mathrm{OH})_{4}$ akan mengalami dehidrasi dan masing-masing membentuk $\mathrm{SnO}$ dan $\mathrm{SnO}_{2}$ :

$$
\begin{aligned}
& \mathrm{Sn}(\mathrm{OH})_{2}+2 \mathrm{OH}^{-}+2 \mathrm{e}^{-} \rightarrow \mathrm{Sn}(\mathrm{OH})_{4} \\
& \mathrm{Sn}(\mathrm{OH})_{2}+2 \mathrm{OH}^{-} \rightarrow \mathrm{SnO}+\mathrm{H}_{2} \mathrm{O} \\
& \mathrm{Sn}(\mathrm{OH})_{4} \rightarrow \mathrm{SnO}_{2}+2 \mathrm{H}_{2} \mathrm{O}
\end{aligned}
$$

Oleh sebab pemelarutan $\mathrm{Sn}(\mathrm{OH})_{2}$ yang rendah, ion $\mathrm{Sn}^{2+}$ akan terlepas dan bergerak ke arah katod. Apabila
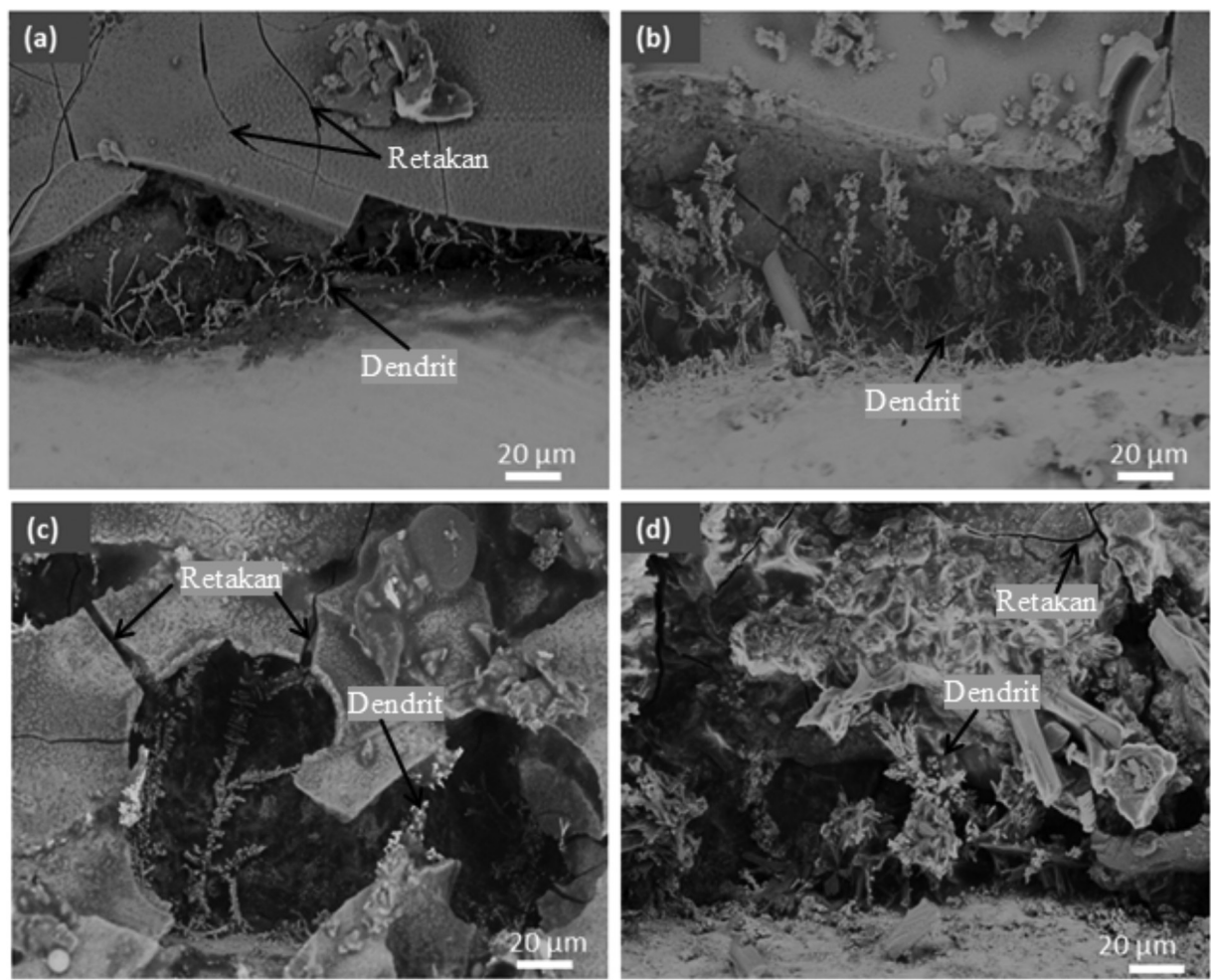

RAJAH 4. Morfologi permukaan dan pembentukan dendrit pada pateri SAC305 selepas didedahkan kepada (a) $0.05 \mathrm{M}$, (b) $0.1 \mathrm{M}$, (c) $0.5 \mathrm{M}$ dan (d) $1.0 \mathrm{M}$ larutan $\mathrm{NaOH}$ 
ion-ion ini tiba di katod, pemendapan elektrokimia berlaku. Pemendapan di katod ini akan membentuk dendrit yang tumbuh ke arah anod, lalu mengakibatkan litar pintas setelah pertumbuhan dendrit sampai ke anod (Noh \& Fung 2008; Yu et al. 2006).

Berdasarkan Jadual 2, unsur-unsur yang terdapat dalam pateri SAC305 yang didedahkan di dalam $0.05 \mathrm{M}$ dan $0.1 \mathrm{M}$ larutan $\mathrm{NaOH}$ adalah sama. Tambahan unsur natrium (Na) dan oksigen $(\mathrm{O})$ daripada keputusan EDX disebabkan oleh medium larutan $\mathrm{NaOH}$ yang dititiskan ke atas sampel untuk menjalankan ujian WD. Kehadiran oksigen (dalam peratusan atom) adalah paling tinggi berbanding unsurunsur yang lain. Hal ini disebabkan oleh tindak balas kakisan yang berlaku memerlukan oksigen dan seterusnya membentuk sebatian oksida. Kehadiran unsur tembaga $\mathrm{Cu}$ ) dan oksigen dalam sampel telah membuktikan hasil kakisan yang berwarna biru itu adalah kuprum hidroksida $\mathrm{Cu}(\mathrm{OH})_{2}$, seperti yang ditunjukkan dalam Rajah 3(a) dan 3(b) Menurut Medgyes et al. (2013), $\mathrm{Cu}(\mathrm{OH})_{2}$ biasanya terbentuk pada permukaan semasa proses ECM:

$$
\mathrm{Cu}_{2} \mathrm{O}+3 \mathrm{H}_{2} \mathrm{O} \rightarrow 2 \mathrm{Cu}(\mathrm{OH})_{2}+2 \mathrm{H}^{+}+2 \mathrm{e}^{-}
$$

dengan keseimbangan

$$
\mathrm{Cu}(\mathrm{OH})_{2} \rightleftharpoons \mathrm{Cu}^{2+}+2 \mathrm{OH}^{-}
$$

Peratusan berat stanum ( $\mathrm{Sn})$ dan $\mathrm{O}$ adalah paling tinggi dalam setiap pateri SAC305 yang didedahkan dalam larutan $\mathrm{NaOH}$ yang berlainan kepekatan. Hal ini menunjukkan Sn adalah unsur dominan yang menyumbang kepada pembentukan dendrit. Oleh sebab itu, berdasarkan analisis EDX, boleh disimpulkan bahawa $\mathrm{Sn}$ dan $\mathrm{O}$ adalah dua unsur terpenting yang menyebabkan pembentukan dan pertumbuhan dendrit. Peningkatan kepekatan ion yang agresif meningkatkan kuantiti dan ketebalan struktur dendrit. Walau bagaimanapun, dalam persekitaran yang terlalu mengkakis, bukan sekadar mengakibatkan perlarutan aloi pateri dan pembentukan dendrit malah menyebabkan kesan kakisan yang lebih teruk seperti pembentukan kakisan bopeng (Vimala et al. 2009). Rajah 5 juga menunjukkan kesan kakisan terhadap pateri SAC305 selepas dijalankan ujian titisan air dengan menggunakan 1.0 M NaOH. Bopeng kecil dan banyak retakan dijumpai pada permukaan papan ujian selepas kakisan. Jung et al.

JADUAL 2. Analisa EDX sampel selepas ujian WD dalam larutan $\mathrm{NaOH}$

\begin{tabular}{ccccccccc}
\hline \multirow{2}{*}{ Unsur } & \multicolumn{2}{c}{$0.01 \mathrm{M}$} & \multicolumn{2}{c}{$0.1 \mathrm{M}$} & \multicolumn{2}{c}{$0.5 \mathrm{M}$} & \multicolumn{2}{c}{$1.0 \mathrm{M}$} \\
\cline { 2 - 9 } & $\%$ wt. & $\%$ at. & $\%$ wt. & $\%$ at. & $\%$ wt. & $\%$ at. & $\%$ wt. & $\%$ at. \\
\hline O K & 44.24 & 79.31 & 44.00 & 81.00 & 45.47 & 79.45 & 46.12 & 74.18 \\
Na K & 5.99 & 7.48 & 4.41 & 5.65 & 8.07 & 9.99 & 15.22 & 17.03 \\
Cu L & 5.29 & 2.39 & 2.11 & 0.98 & 7.98 & 2.56 & 2.07 & 0.84 \\
Ag L & 3.37 & 0.90 & 3.69 & 1.01 & 2.10 & 0.40 & 0.83 & 0.20 \\
Sn L & 41.10 & 9.93 & 45.79 & 11.36 & 36.38 & 7.61 & 35.77 & 7.75 \\
\hline
\end{tabular}
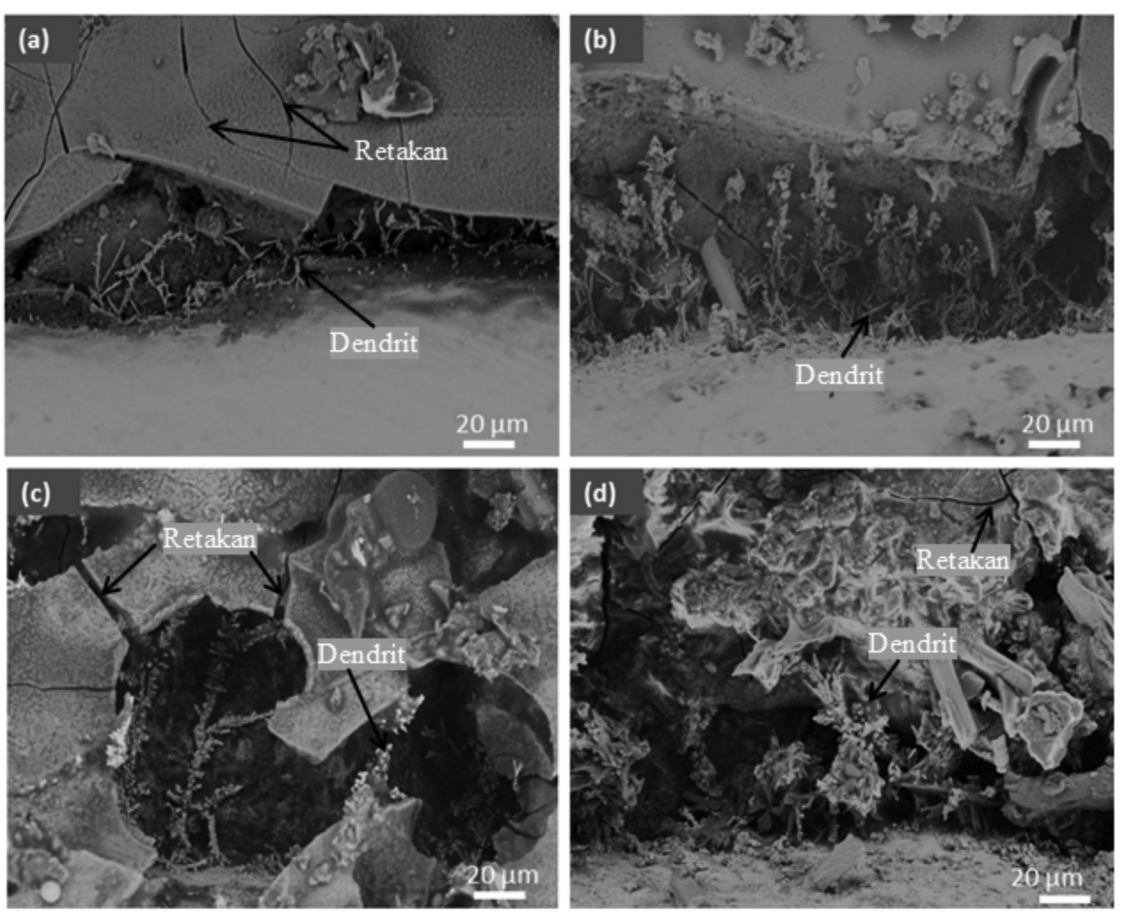

RAJAH 5. Morfologi pateri SAC305 selepas ujian WD dengan menggunakan 1.0M NaOH 
(2008) membuktikan bahawa rantau perlarutan pada anod $\mathrm{Sn}$ mempamerkan pembentukan bopeng-bopeng kecil semasa ujian WD di dalam larutan berkepekatan tinggi.

\section{KESIMPULAN}

Dalam kajian ini, pateri SAC305 telah dijalankan ujian titisan air dengan menggunakan kepekatan medium larutan natrium hidroksida yang berbeza. Purata masake-kegagalan pateri SAC305 berkurangkan dengan peningkatan kepekatan larutan $\mathrm{NaOH}$. Urutan MTTF bagi pateri SAC305 berlakunya ECM adalah:

$$
1.0 \mathrm{M}>0.5 \mathrm{M}>0.1 \mathrm{M}>0.05 \mathrm{M}
$$

Mendakan $\mathrm{Cu}(\mathrm{OH})_{2}$ yang berwarna biru didapati terbentuk pada permukaan pateri SAC305 selepas kakisan di dalam larutan $\mathrm{NaOH}$ berkepekatan $0.05 \mathrm{M}$ dan 0.1M. Pembentukan hasil kakisan $\mathrm{SnO}_{2}$ yang berwarna kabur putih didapati mendominasi permukaan setiap pateri. Pembentukan dendrit dikenal pasti akibat proses ECM yang menjadi faktor utama berlakunya kegagalan peranti melalui litar pintas. Bentuk dendrit yang diperhatikan adalah berbentuk batang lurus dengan cabangan yang tumbuh dalam arah menegak. Pembentukan bopeng kecil pada permukaan pateri yang terdedah kepada larutan $\mathrm{NaOH}$ terutamanya pada kepekatan yang tinggi adalah disebabkan oleh perlarutan pada anod Sn.

\section{PENGHARGAAN}

Penulis merakamkan penghargaan kepada Universiti Kebangsaan Malaysia (UKM) dan Kementerian Pendidikan Malaysia atas geran penyelidikan [FRGS/1/2016/STG07/ UKM/02/1] dan [FRGSTOPDOWN/2014/ SG06/UKM/03/1].

\section{RUJUKAN}

Anderson, I.E. 2006. Development of Sn-Ag-Cu and Sn-Ag-Cu-X alloys for $\mathrm{Pb}$-free electronic solder applications. Lead-Free Electronic Solders 27: 55-76.

Jung, J., Lee, S., Lee, H., Joo, Y. \& Park, Y. 2008. Anodic dissolution characteristics and electrochemical migration lifetimes of $\mathrm{Sn}$ solder in $\mathrm{NaCl}$ and $\mathrm{Na}_{2} \mathrm{SO}_{4}$. Microelectronic Engineering 85: 1597-1602.

Lee, L.M. \& Mohamad, A.A. 2013. Interfacial reaction of Sn$\mathrm{Ag}-\mathrm{Cu}$ lead-free solder alloy on $\mathrm{Cu}$ : A review. Advances in Materials Science and Engineering Article: Article ID. 123697.

Liew, M.C., Ahmad, I., Lee, L.M., Nazeri, M.F.M., Haliman, H. \& Mohamad, A.A. 2012. Corrosion behaviour of Sn-3.0Ag$0.5 \mathrm{Cu}$ lead-free solder in potassium hydroxide electrolyte. Metallurgical and Materials Transactions A 43(10): 37423747.

Ma, H. \& Suhling, J.C. 2009. A review of mechanical properties of lead-free solders for electronic packaging. Journal of Materials Science 44: 1141-1158.

Medgyes, B., Illes, B. \& Harsanyi, G. 2013. Electrochemical migration of micro-alloyed low $\mathrm{Ag}$ solders in $\mathrm{NaCl}$ solution. Electrical Engineering 57: 1-7.
Minzari, D., Jellesen, M.S., Moller, P. \& Ambat, R. 2011. On the electrochemical migration mechanism of tin in electronics. Corrosion Science 53: 3366-3379.

Mohanty, U.S. \& Lin, K. 2008. Electrochemical corrosion behaviour of Pb-free Sn-8.5Zn-0.05Al-XGa and Sn-3Ag$0.5 \mathrm{Cu}$ alloys in chloride containing aqueous solution. Corrosion Science 50: 2437-2443.

Nazeri, M.F.M., Affendy, M.G. \& Mohamad, A.A. 2012. Corrosion study of Sn-9Zn lead-free solder in alkaline solution. International Journal of Electrochemical Science 7: 4182-4191.

Noh, B. \& Fung, S. 2008. Behaviour of electrochemical migration with solder alloy on printed circuit boards (PCBs). Circuit World 34(4): 8-13.

Rosalbino, F., Angelini, E., Zanicchi, G., Carlini, R. \& Marazza, R. 2009. Electrochemical corrosion study of $\mathrm{Sn}-3 \mathrm{Ag}-3 \mathrm{Cu}$ solder alloy in $\mathrm{NaCl}$ solution. Electrochimica Acta 54: 7231-7235.

Tsao, L.C. 2012. Corrosion resistance of Pb-free and novel nano-composite solders in electronic packaging. www. intechopen.com.

Vimala, J.S., Natesan, M. \& Rajendran, S. 2009. Corrosion and protection of electronic components in different environmental conditions: An overview. The Open Corrosion Journal 2: 105-113.

Wang, M., Wang, J., Feng, H. \& Ke, W. 2012. Effects of microstructure and temperature on corrosion behavior of Sn3.0Ag-0.5Cu lead-free solder. Journal of Materials Science: Materials in Electronics 23: 148-155.

Xue, P., Xue, S., Zhang, L., Shen, Y., Gao, L., Yu, S., Zhu, H., Han, Z. \& Chen, Y. 2011. Tensile strength of fine pitch QFP lead-free soldered joints with diode laser soldering. Soldering and Surface Mount Technology 23(3): 177-183.

Yu, D.Q., Jillek, W. \& Schmitt, E. 2006. Electrochemical migration of lead free solder joints. Journal Materials Science: Materials in Electronics 17: 229-241.

Emee Marina Salleh \& Norinsan Kamil Othman*

School of Applied Physics

Faculty of Science and Technology

Universiti Kebangsaan Malaysia

43600 UKM Bangi, Selangor Darul Ehsan

Malaysia

Azman Jalar

Institute of Microengineering and Nanoelectronic (IMEN)

Universiti Kebangsaan Malaysia

43600 UKM Bangi, Selangor Darul Ehsan

Malaysia

*Pengarang untuk surat-menyurat; email: insan@ukm.my

Diserahkan: 5 Oktober 2017

Diterima: 27 April 2018 